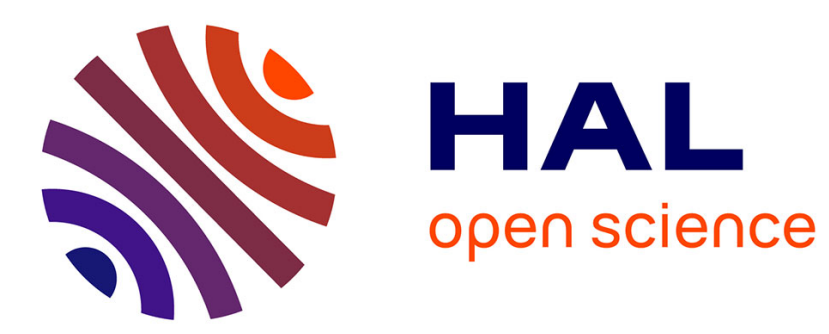

\title{
Botulinum toxin type A induces direct analgesic effects in chronic neuropathic pain.
}

Danièle Ranoux, Nadine Attal, Françoise Morain, Didier Bouhassira

\section{To cite this version:}

Danièle Ranoux, Nadine Attal, Françoise Morain, Didier Bouhassira. Botulinum toxin type A induces direct analgesic effects in chronic neuropathic pain.. Annals of Neurology, 2008, 64 (3), pp.274-83. 10.1002/ana.21427 . inserm-00292356

\section{HAL Id: inserm-00292356 https://www.hal.inserm.fr/inserm-00292356}

Submitted on 1 Jul 2009

HAL is a multi-disciplinary open access archive for the deposit and dissemination of scientific research documents, whether they are published or not. The documents may come from teaching and research institutions in France or abroad, or from public or private research centers.
L'archive ouverte pluridisciplinaire $\mathbf{H A L}$, est destinée au dépôt et à la diffusion de documents scientifiques de niveau recherche, publiés ou non, émanant des établissements d'enseignement et de recherche français ou étrangers, des laboratoires publics ou privés. 


\section{BOTULINUM TOXIN A INDUCES DIRECT ANALGESIC EFFECTS IN}

\section{CHRONIC NEUROPATHIC PAIN}

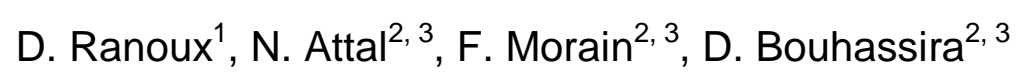

${ }^{1}$ Services de neurologie, neurochirurgie et soins palliatifs, CHU Limoges, France ; ${ }^{2}$ INSERM U-792, Boulogne-Billancourt F-92100 France; CHU Ambroise Paré, APHP, Boulogne-Billancourt, F-92100 France; 3 Université Versailles-Saint-Quentin, Versailles F-78035, France

Correspondence to:

Nadine ATTAL

INSERM U-792

Centre de Traitement et d'Evaluation de la Douleur,

$\mathrm{CHU}$ Ambroise Paré

9, avenue Charles de Gaulle

92100 Boulogne-Billancourt cedex, France

telephone number: +33149094556

fax number: +33149094435

e-mail: didier.bouhassira@apr.aphp.fr 


\section{SUMMARY}

Objectives: Botulinum toxin A (BTX-A) has been reported to have analgesic effects independent of its action on muscle tone, possibly by acting on neurogenic inflammation. Such mechanism may be involved in peripheral neuropathic pain.

Methods: A possible direct analgesic effect of BTX-A pain processing was investigated in 29 patients with focal painful neuropathies and mechanical allodynia using a randomized double-blind placebo-controlled design. Patients received a one time intradermal administration of BTX-A (20 to 190 units) into the painful area. Outcome measures, evaluated at baseline, then at 4, 12 and 24 weeks, included average spontaneous pain intensity, quantified testing of thermal and mechanical perception and pain, allodynia to brushing (area, intensity), neuropathic symptoms, clinical global impression and quality of life.

Results : BTX-A treatment, relative to placebo, was associated with persistent effects on spontaneous pain intensity from 2 weeks after the injection to 14 weeks. These effects correlated with the preservation of thermal sensation at baseline $(p<0.05)$. BTX also improved allodynia to brush and decreased pain thresholds to cold, without affecting perception thresholds. There were sustained improvements in the proportion of responders (Number Needed to Treat for $50 \%$ pain relief: 3.03 at 12 weeks), neuropathic symptoms and general activity. Most patients reported pain during the injections, but there were no further local or systemic side effects.

Interpretation: These results indicate for the first time that BTX-A may induce direct analgesic effects in patients with chronic neuropathic pain independent on its effects on muscle tone and suggest novel indications for BTX-A in analgesia.

Key words: neuropathic pain - botulinum toxin A - double blind randomized study allodynia

Word count : abstract words 254 ; manuscript words : 3369 


\section{INTRODUCTION}

Botulinum toxin type A (BTX-A), a potent neurotoxin, is commonly used for the treatment of focal muscle hyperactivity, particularly dystonia and spasticity $(1,2)$ and the management of glandular hyperactivity, including hyperhidrosis (3). The beneficial effect of BTX-A in these conditions is believed to result from the blockade of presynaptic nerve terminals releasing acetylcholine $(4,5,6)$. However, early in the use of BTX-A for dystonia, some authors noted that pain relief preceded muscle decontraction and exceeded what would have been expected solely as a consequence of muscle relaxation (4). These findings suggested that BTX-A might have analgesic properties independent of its myorelaxant action. Further information came from in vitro experiments demonstrating that BTX-A could inhibit neurogenic inflammation, a process that results from the sensitization of C-fiber nociceptors (7); the effects of BTX-A involved attenuation of the release of neurotransmitters

including SP $(8,9)$, CGRP $(10,11)$ and glutamate $(12)$ and inhibition of vanilloid receptor activity (13). Consistent with these in vitro experiments, peripheral injections of BTX-A reduces nociceptive behaviors in animal models of inflammatory $(12,14)$ and traumatic neuropathic pain $(15,16,17)$.

Neurogenic pain mechanisms may play a role in neuropathic pain due to peripheral nerve lesions (18), particularly those associated with allodynia, such as postherpetic neuralgia and post-traumatic/post-operative nerve lesions $(18,19,20$, 21). These chronic pain conditions are significant causes of focal painful neuropathies $(22,23)$ and are very difficult to treat and often devastating $(24,25,26)$. In most cases, the area involved is limited, and thus local injections of BTX-A may be suitable. The efficacy of BTX-A in neuropathic pain has only been suggested in small anecdotal case reports $(27,28,29,30)$. 
In the present study, we investigated for the first time the potential direct analgesic effects of one-time BTX-A in the painful area in patients with focal neuropathic pain (eg, post-traumatic/post-operative pain or postherpetic neuralgia) associated with allodynia using a double blind placebo controlled parallel group design. In order to exclude effects on muscle tone, the injections were performed intradermally. 


\section{PATIENTS AND METHODS}

This study was conducted at Ambroise Paré Hospital, Boulogne-Billancourt and was approved by local ethics committee. Patients were recruited between June 2004 and October 2006 by means of physician referrals and provided written informed consent before inclusion.

\section{Patients}

Consecutive patients with postherpetic neuralgia or post-traumatic/postoperative neuropathies confirmed by appropriate clinical and paraclinical examination when necessary (e.g. EMG) were recruited and gave written informed consent. Criteria for inclusion were daily pain for at least six months (numerical score of at least 3 out of 10) clearly attributed to the nerve lesion, limited area of pain (not exceeding $60 \mathrm{~cm} 2$, corresponding to the maximal doses of BTX-A as indicated below) and mechanical allodynia in the painful area. Exclusion criteria were contraindication for BTX-A (i.e. diseases of the neuromuscular junction), hypersensitivity to the BTX-A formulation, coagulation disorders, any other painful condition, current major depression, a history of serious drug or alcohol abuse, compensation claim or litigation, and facial pain (due to potential increased side effects of BTX-A in this area). Concomitant analgesic medication was authorized, provided the dose was stable for at least 1 month before enrollment and throughout the study. Treatments acting on neuromuscular junctions and topical medications or procedural therapies (e.g. anesthetic blocks) were forbidden.

\section{Protocol}

A randomised double-blind placebo-controlled parallel group design was used. A total of 4 visits was scheduled over 24 weeks (at baseline, and after 4, 12 and 24 weeks). During the 7-day baseline period, all patients underwent testing for allodynia 
and were asked to record their pain intensity in a diary; eligible patients were then randomly assigned to two groups - one given the active drug and the other the placebo. A pharmacist prepared a concealed allocation schedule randomly assigning the treatments in blocks of four, to a consecutive series of numbers. The treatment allocation code was kept in a sealed envelope until the completion of the study.

Treatment was administered by a neurologist not involved in the assessment. Aliquots of 100 units/vial Botulinum toxin A (BOTOX, Allergan) were reconstituted with $4 \mathrm{ml}$ non preserved saline solution $(0.9 \%)$ as recommended by the manufacturer (concentration of 5 units BTX-A /0.2 ml) and placebo consisted of an equal volume of saline $(9 \% \mathrm{NaCl})$. The injection of $\mathrm{BTX}-\mathrm{A}$ or saline was performed according to a procedure adapted from that used for hyperhidrosis (31) : BTX-A or placebo was injected intracutaneously into the skin $1.5 \mathrm{~cm}$ apart $(0.2 \mathrm{ml}$ and thus 5 units of BTX-A per site) (Figure 1). We first mapped with a pen the exact area of mechanical allodynia for all patients. We then determined the number of injections so as to cover the whole allodynic area, without exceeding the predetermined maximum number of sites, which was fixed at 40 (corresponding to a dose of 200 units).

The two solutions were limpid and indistinguishable. The injection syringes were prepared by the pharmacist in such a way that the physician performing the injection could not recognize the treatment. Patients and the investigator were blind to the treatments throughout the study.

To minimize the pain due to injections, all patients received a cream formulation of lidocaine and prilocaine (EMLA) applied to the painful area 60 minutes before the injections; also a nurse administered an equimolar mix of nitrous oxide and oxygen $\left(\mathrm{N}_{2} \mathrm{O} / \mathrm{O}_{2}\right)$ via a high-concentration mask for 5 minutes before the beginning and throughout the procedure. 


\section{Outcome measures}

The primary outcome measure was self-reported average pain intensity from each morning's record in a diary concerning the last 24 hours using the 11 point numerical scale (0: no pain; 10: maximal pain imaginable) of the Brief Pain Inventory (BPI) (32).

Sensory deficits and pain were measured and assessed by the same investigator at baseline, and after 4 and 12 weeks, as in prior therapeutic trials (33, 34). Brush-induced allodynia was evaluated by stroking the skin with a standardized brush (Senselab brush-0.5, Somedic, Sweden) and was considered as present if this evoked a clear sensation of pain. The intensity of allodynia (recorded on a $100 \mathrm{~mm}$ visual analog scale) and its area (traced on a transparent paper, then digitized for measurement on Canvas 6.0 software) were measured. Mechanical sensations (detection thresholds to non painful stimuli) and pain thresholds were measured with calibrated von Frey hairs (0.06 to $300 \mathrm{~g}$ ) (Somedic AB, Sweden). Thermal sensations and pain thresholds (in ${ }^{\circ} \mathrm{C}$ ) were assessed with a Somedic thermotest (Somedic $A B$, Sweden) by the method of limits, with baseline temperatures adjusted to the patient's skin temperature according to a procedure largely described elsewhere (35). Measurements obtained in the area of maximal pain were compared to those of the homologous contralateral side.

Other secondary outcome measures (completed at baseline and follow-up visits) included: a visual analog scale rating the average pain over the last 24 hours on a 100-mm line; the neuropathic pain symptom inventory (NPSI) (36) rating the mean intensity of 10 neuropathic symptoms and their combination into 5 distinct dimensions during the last 24 hours on 11-point $(0-10)$ numerical scales; the duration 
of spontaneous pain and number of pain paroxysms (assessed with the NPSI on categorical scales); six of seven items for pain interference of the BPI (with the exclusion of the item "ability to walk" judged irrelevant here) rated from 0 (does not interfere), to 10 (complete interference); the Hospital Anxiety and Depression Scale (HAD) (37) including 14 items scored as anxiety and depression scores (each on 21); subjective pain relief due to the treatment over the past week (from $0 \%$ (no pain relief) to $100 \%$ (maximal pain relief)); the patients' overall impression of change (PGIC) on a 7-point scale (from very much improved to very much worse); and the assessment of blindedness.

The safety of BTX-A, particularly with regards to potential systemic side effects, was assessed throughout the study. Pain related to injections was rated as mild, moderate or severe.

\section{Statistical analysis}

Baseline clinical and demographic variables were compared by Fisher's exact test or an unpaired t-test. The primary outcome measure was the change in the weekly averages of the daily ratings of pain on numerical scales from the baseline week through the $24^{\text {th }}$ week of treatment. Changes in primary and secondary outcome measures (quantified measures of deficits and pains, pain scores, symptoms, quality of life, mood) expressed as differences between baseline and the values obtained at each time point were analyzed using a repeated measures analysis of variance (ANOVA) in which the factors were treatment group (BTX-A or placebo) and time at specified time points (ie, 4, 12 and 24 weeks, except for quantified measures which were not repeated at 24 weeks). Analyses of variance with the Bonferroni correction were used for post hoc comparisons. The Spearman rank correlation test was used to analyze the correlations between pairs of variables. 
The proportion of responders was defined as patients with $\geq 50 \%$ reduction in weekly mean pain scores and Numbers Needed to Treat (NNT) were provided for 50 $\%$ pain relief. Fisher's exact test was used to compare categorical variables. The intent to treat (ITT) population analysed for efficacy included all randomized patients who had a baseline evaluation and at least one post-baseline visit. Subjects who discontinued prematurely from the study were analysed in two ways : a/ Last observation carried forward (LOCF) : the last observation before the time of discontinuation was carried forward to the end of the study period from which they discontinued ; b/Observed data : data were regarded as missing and no values were imputed. For the primary and secondary end points, analysis was performed in the ITT population with both the LOCF approach (primary analysis) and observed data (additional analysis). In all cases, $\mathrm{P}$ values $<0.05$ were considered significant.

This study is registered with Clinicaltrials.gov, number NCT0057202.

Funding source and access to data : The study received financial support from Institut National de la Santé et de la Recherche Médicale (INSERM). All the authors had full access to all the data in the study and they held final responsibility for the decision to submit for publication. 


\section{Results}

We screened 61 consecutive patients (Figure 2), of whom 29 (19 women, 10 men) fulfilling the inclusion criteria were randomly assigned to BTX-A or placebo groups. Sociodemographic variables, pain characteristics, etiology and analgesic treatments did not differ between the two groups (Tables 1 and 2). Seven patients withdrew from the study before 24 weeks (Figure 2).

\section{Doses and injections}

The mean $( \pm \mathrm{SD})$ number of injection sites was $20 \pm 8.3$ for BTX-A (with dosages ranging from 20 to 190 units) and $19.8 \pm 5.2$ for the placebo. The total volumes of injection were also similar for BTX-A $(4.4 \pm 1.6)$ and the placebo $(3.9 \pm$ $1.1)$

\section{Pain intensity}

As shown in Figure 3A, BTX-A improved weekly average pain intensity throughout the study in comparison with the placebo ( $p=0.038$, LOCF analysis) (Figure 3A). The improvement of pain was significant at several time points (posthoc analysis), starting from week $2(p=0.025)$. The effect increased therafter for up to 4 weeks $(p=0.036)$, remained stable for up to 14 weeks (the mean pain scores decreased by $1.9 \pm 1.9$ with BTX-A compared to $0.3 \pm 1.8$ with the placebo; $p=0.03$ ), then was no longer significant (LOCF approach), but remained significant in analysis of observed cases ( $p=0.046$ at 24 weeks). Higher proportions of patients were responders to BTX-A than to placebo (Table 2), and these proportions increased between 4 and 12 weeks (Figure 3B). The NNT for $50 \%$ pain relief with BTX-A was $3.70(2.04-23.2)$ at 4 weeks and $3.03(1.64-21.6)$ at 12 weeks. One patient treated with BTX-A became pain-free after 12 weeks (no patient was pain-free with the 
placebo) (Table 2).

Effects on quantified measures of perception and pain

The area and intensity of allodynia to brush and cold pain thresholds on the painful side were reduced in the group treated with BTX-A (Figure 4). There was no effect on thresholds to non painful thermal and mechanical stimuli or on heat and mechanical pain thresholds on either side (not shown).

\section{Other outcomes}

BTX-A significantly improved average pain intensity assessed at each follow up visit $(p=0.0073$, repeated measures ANOVA) and provided global pain relief (Table 3). After 12 weeks, $40 \%$ of patients receiving BTX-A (and $14 \%$ with the placebo) rated themselves as much or very much improved, $53 \%$ were unchanged or worse (78\% with the placebo) and $7 \%$ minimally improved $(7 \%$ with the placebo). Three dimensions of the NPSI (burning, paroxysmal pain, allodynia) corresponding to 5 neuropathic symptoms, improved in the BTX-A group while other dimensions (deep pain, paresthesia/dysesthesia) were unaffected (Table 3). The number of pain paroxysms was also reduced $(p=0.05$ at 4 weeks; $p=0.042$ at 12 weeks ; $p=0.039$ at 24 weeks), although pain duration was unaffected. BTX-A also improved some markers of quality of life including general activity and mood (Table 3). The effect of BTX-A on general activity correlated with the improvement of average pain intensity (Rho : $0.71 ; p=0.008$ at 4 weeks; Rho $: 0.43 ; p=0.02$ at 12 weeks). Anxiety scores of the HAD slightly improved in the BTX-A group but tended to worsen in the placebo group while the depression scores remained unchanged (Table 3). 


\section{Exploratory analysis of the predictive factors for BTX-A analgesic effects}

The effects of BTX-A on average pain intensity did not differ between sexes and did not correlate with the age, duration or intensity of pain or neuropathic symptoms. However, they were inversely correlated with the magnitude of thermal deficits on the painful side at baseline (Figure 3C). Similar inverse correlations were observed regarding burning pain (Rho : -0.83 at 4 weeks $; p=0.018$; Rho $=-0.80$ at 12 weeks $; p=0.003$ and Rho : -0.79 at 24 weeks $; p=0.008$ ) and brush evoked pain (Rho : -0.66 at 12 weeks ; $p=0.018$; Rho : -0.59 at 24 weeks ; $p=0.048)$. This suggested that the better the thermal sensation at baseline was preserved, the better the analgesic effects of BTX-A.

\section{Study safety and assessment of blindedness}

Most patients reported that the injections were painful, with no difference between BTX-A (mild pain: 7, moderate pain: 4, severe pain: 2) and placebo (mild pain: 6 , moderate pain: 4 , severe pain: 2 ) groups. The severity of pain was related to the site of injection, being greater when at the hands or elbow. No other local or systemic side effects were reported during the injection or at any other time during the study. Seven patients experienced mild side effects associated with the anesthetic procedure (euphoria: 3 patients with placebo, 3 with BTX-A; anxiety: 1 patient with BTX-A).

No patient was able to recognize the active treatment from side effects and seven patients (five with BTX-A) thought they had received BTX-A because of improvement. The other patients were unable to state which drug they had received. 


\section{Discussion}

The present study aimed to investigate the potential direct analgesic effects of BTXA in patients with focal neuropathic pain using a randomized, double-blind, placebo-controlled design. Our main findings showed that one-time intradermal injections of BTX-A induce long-lasting analgesic effects counteracting focal chronic neuropathic pain. These effects involved self-assessment of pain and clinician-based quantified measures. In particular we observed a reduction of the intensity and area of mechanical allodynia and a decrease in cold pain thresholds on the painful side, while perception thresholds were not modified. These features indicate that BTX-A has selective effects on pathological pain processing. Moreover several neuropathic symptoms and some measures of quality of life improved. Our data indicate new potential mechanisms of BTX-A in analgesia. They also suggest novel therapeutic indications for BTXA.

In the present study, we found that the preservation of thermal sensibility at baseline was correlated with the analgesic effects of BTX-A, e.g. patients with less impaired sensory deficits were better responders. This observation is in keeping with recent preclinical data, showing that BTX-A blocks the protein kinase $\mathrm{C}$ potentiation of Transient Receptor Potential Vanilloid 1 (TRPV1), a capsaicin and heat sensitive ion channel expressed in nociceptors, that participates in the transduction of thermal stimuli by sensory nerve endings (13). It is thus possible that BTX-A acts on sensitized nociceptive fibers to produce its analgesic effects. This mechanism could also account for the early effect of BTX on pain observed here, as soon as week 2 after the injection. In keeping with our results, recent studies using models of experimental pain in healthy subjects showed that BTX-A reduces capsaicin-evoked pain and neurogenic vasodilatation in human skin $(38,39)$. However, several other 
studies using various experimental models of pain $(40,41,42,43,44)$ yielded negative results. Several reasons may account for these discrepancies, including the use of different preparations of BTX, which are not bioequivalent (45) and the application of different experimental stimuli. However, the main reason may be that the binding of BTX to its protein receptors (46), the key step for its analgesic effects, is probably greater in chronic pathological pain than in acute experimental pain. It is thus difficult to translate data from experimental pain in healthy volunteers to sustained pathological pain $(5,6,47)$. In any case, a possible central target for the action for BTX-A cannot be ruled out (4), particularly since several of our patients showed improved relief over time after one-time administration. Work in animals and humans is necessary to elucidate the mechanisms of the analgesic effects of BTX-A in neuropathic pain.

BTX is generally administered as intramuscular injection for focal spasticity or dystonia $(1,2)$. Since our patients presented with superficial pain and allodynia, and in order to exclude possible secondary effects of BTX on muscle tone, we used intradermal injections of BTX, matched to the extent of the painful area, according to a procedure recommended for hyperhidrosis $(3,31)$. This procedure was safe and relevant for our patients, although it may only be suitable for patients with focal neuropathies, where the extent of pain is limited. It remains to be established whether this mode of administration can also be used for patients with larger areas of pain, such as those with painful polyneuropathies.

Neuropathic pain is a common chronic pain condition affecting up to $7-8 \%$ of the general population $(48,49)$ with a devastating impact on quality of life and substantial socioeconomic costs $(50,51)$. First-line treatments include antiepileptics or antidepressants $(24,25,52)$. However, these treatments have limited 
effectiveness: they reduce pain more than placebo in less than $30 \%$ of patients and are relatively frequently associated with side effects $(24,25)$. Topical analgesics such as lidocaine patches or capsaicin may be proposed, particularly for focal neuropathies, but their efficacy is modest (24). BTX-A appears to have significant advantages over existing treatments, at least on the basis of the present study which included a highly selective group of patients with allodynia. One is the extended duration of its analgesic effects despite a one-time administration, with several patients still reporting improvement at 24 weeks. The efficacy of BTX-A also seems to compare favorably with that of other treatments, with a NNT for $50 \%$ pain relief of 3 at 12 weeks. Finally, the drug was very well tolerated: the only notable side-effect was moderate to severe transient pain during injections in several patients especially when involving the fingers, despite a pretreatment with local anesthetics and administration of nitrous oxide. However, this problem could be overcome with other modes of analgesia, including peripheral nerve blocks, intravenous propofol or lidocaine reconstructed BTX, as used for hyperhidrosis (53). Large scale studies are needed to confirm these results and determine whether BTX-A may also be effective in other forms of neuropathic pain.

We conclude that intradermal injection of BTX-A has direct analgesic effects in patients with focal chronic neuropathic pain associated with allodynia. It is suggested that the observed analgesia may due to a local peripheral effect of BTXA on nociceptive fibers, although subsequent central effects are possible. The treatment was particularly well tolerated. These data suggest that BTXA should be considered as part of the therapeutic arsenal against focal neuropathic states.

Conflicts of interest: DR, NA, DB and FM declare no conflicts of interest related to the study.

Aknowledgements : We are indepted to S. Donnadieu, MD, E. Le Viet, MD, and C. Mathoulin, $\mathrm{MD}$, for patients referral. We thank Allergan (France) for kindly supplying with BTX-A. 


\section{References}

1. Ward AB, Molenaers G, Colosimo C, Berardelli A. Clinical value of botulinum toxin in neurological indications. Eur J Neurol. 2006;13 Suppl 4:20-6.

2. Brashear A, Gordon MF, Elovic E, Kassicieh VD, Marciniak C, Do M, Lee CH, Jenkins S, Turkel C; Botox Post-Stroke Spasticity Study Group. Intramuscular injection of botulinum toxin for the treatment of wrist and finger spasticity after a stroke. N Engl J Med. $2002 ; 347$ :395-400.

3. Heckmann M, Ceballos-Baumann AO, Plewig G; Hyperhidrosis Study Group. Botulinum toxin A for axillary hyperhidrosis (excessive sweating). $\mathrm{N}$ Engl $\mathrm{J}$ Med. 2001;344 :488-93.

4. Aoki KR. Review of a proposed mechanism for the antinociceptive action of botulinum toxin type A. Neurotoxicology. 2005 ; 26 :785-93.

5. Mense S.Neurobiological basis for the use of botulinum toxin in pain therapy. $J$ Neurol. 2004;251 Suppl 1:11-7.

6. Simpson LL. Identification of the major steps in botulinum toxin action. Annu Rev Pharmacol Toxicol. 2004;44:167-93.

7. Handwerker HO Nociceptors : neurogenic inflammation. In : Handbook of clinical neurology, vol 81, Pain, F Cervero; TS Jensen (eds), Elsevier, Amsterdam, 2006, pp. 23-33.

8. Ishikawa $\mathrm{H}$, Mitsui $\mathrm{Y}$, Yoshitomi $\mathrm{T}$, Mashimo $\mathrm{K}$ et al. Presynaptic effects of botulinum toxin type $A$ on the neuronally evoked response of albino and pigmented rabbit iris sphincter and dilator muscles. Jpn J Ophthalmol 2000; $44: 106-9$ 
9. Purkiss J, Welch M, Doward S, Foster K. Capsaïcin-stimulated release of substance $\mathrm{P}$ from cultured dorsal root ganglion neurons : involvement of two distinct mechanisms. Biochem Pharmacol 2000 ; 59 : 1403-1406

10. Meunier FA, Colasante C, Faille L, Gastard M, Molgo J. Upregulation of calcitonin gene related peptide at mouse motor nerve terminals poisoned with botulinum type-A toxin. Pflugers Arch 1996 ; 431 (suppl 2 ): R 297-8.

11. Durham PL, Cady Rand R. Cady, Regulation of calcitonin gene-related peptide secretion from trigeminal nerve cells by botulinum toxin type $A$ : implications for migraine therapy, Headache 2004; 44: 35-42.

12. Cui M, Khanijou S, Rubino J, Aoki KR, Subcutaneous administration of botulinum toxin A reduces formalin-induced pain, Pain 2004; 107: 125-133.

13. Morenilla-Palao C, Planells-Cases R, Garcia-Sanz N, Ferrer-Montiel A. Regulated exocytosis contributes to protein kinase $\mathrm{C}$ potentiation of vanilloid receptor activity. J Biol Chemistry 2004; 279: 25665-25672.

14. Luvisetto S, Marinelli S, Lucchetti F, Marchi F et al. Botulinum neurotoxins and formalin-induced pain : central vs peripheral effects in mice. Brain Res 2006; 1082: 124-131.

15. Bach-Rojecky L, Relja M, Lackovic Z. Botulinum toxin type A in experimental neuropathic pain. J Neural Transm 2005; 112: 215-9.

16. Luvisetto S, Marinelli S, Cobianchi S, Pavone F. Anti-allodynic efficacy of botulinum neurotoxin A in a model of neuropathic pain. Neuroscience 2007; 145: $1-4$.

17. Park HJ, Lee $\mathrm{Y}$, Lee J, Park C, Moon DE. The effects of botulinum toxin A on mechanical and cold allodynia in a rat model of neuropathic pain. Can $\mathrm{J}$ Anesth 2006; 53: 470-77. 
18.Zieglgansberger W, Berthele A, Tolle TR. Understanding neuropathic pain. CNS Spectr. 2005;10:298-308.

19. Cline MA, Ochoa J, Torebjork HE. Chronic hyperalgesia and skin warming caused by sensitized C nociceptors. Brain. 1989;112:621-47.

20. Fields HL, Rowbotham M, Baron R. Postherpetic neuralgia: irritable nociceptors and deafferentation. Neurobiol Dis. $1998 ; 5: 209-27$.

21. Petersen KL, Fields HL, Brennum J, Sandroni P, Rowbotham MC. Capsaicin evoked pain and allodynia in post-herpetic neuralgia. Pain. 2000 ;88:125-33.

22. Hempenstall K, Nurmikko TJ, Johnson RW, A'Hern RP, Rice AS. Analgesic therapy in postherpetic neuralgia: a quantitative systematic review. PLoS Med. $2005 ; 2: 164$

23. Kehlet $\mathrm{H}$, Jensen TS, Woolf CJ. Persistent postsurgical pain: risk factors and prevention. Lancet 2006 ; $367:$ 1618-25.

24. Attal N, Haanpaa M, Hansson P, Jensen TS et al. EFNS guidelines on pharmacological treatment of neuropathic pain. Eur J Neurology $2006 ; 13$ : 1153-69.

25. Finnerup NB, Otto M, McQuay HJ et al. Algorithm for neuropathic pain treatment: an evidence based proposal. Pain $2005 ; 118$ : 289-305.

26. Hall GC, Carroll D, Parry D, McQuay HJ. Epidemiology and treatment of neuropathic pain: the UK primary care perspective. Pain $2006 ; 122: 156-62$.

27. Argoff CE. A focused review on the use of botulinum toxins for neuropathic pain. Clin J Pain. 2002;18 :S177-81.

28. Freund B, Schwartz M. Subcutaneous BTX-A in the treatment of neuropathic pain: a pilot study. Presented at the 38th Interagency Botulism Research Coordinating meeting. October 17-19, 2001. Easton, Maryland. 
29. Jabbari B, Maher N, Difazio MP. Botulinum toxin A improved burning pain and allodynia in two patients with spinal cord pathology. Pain Med 2003; 4: 206210

30.Liu HT, Tsai SK, Kao MC, Hu JS. Botulinum toxin A relieved neuropathic pain in a case of post-herpetic neuralgia. Pain Med 2006; 7: 89-91

31. Naumann M, Flachenecker P, Brocker EB, Toyka KV, Reiners K. Botulinum toxin for palmar hyperhidrosis. Lancet. 1997;349:252.

32. Attal N, Rouaud J, Brasseur L, Chauvin M, Bouhassira D. Systemic lidocaine in pain due to peripheral nerve injury and predictors of response. Neurology $2004 ; 62: 218-25$.

33. Wallace MS, Rowbotham MC, Katz NP, Dworkin RH et al. A randomized, double-blind, placebo-controlled trial of a glycine antagonist in neuropathic pain. Neurology $2002 ; 59: 1694-700$.

34. Cleeland CS, Ryan KM. Pain assessment: global use of the Brief Pain Inventory. Ann Acad Med Singapore $1994 ; 23$ : 129-38.

35. Ducreux D, Attal N, Parker F, Bouhassira D. Mechanisms of central neuropathic pain: a combined psychophysical and fMRI study in syringomyelia. Brain 2006:129-963-976

36. Bouhassira D, Attal N, Fermanian J, Al-Chaar M et al. Development and validation of the Neuropathic Pain Symptom Inventory. Pain 2004 ; 108 : 24857.

37.Zigmond AS, Snaith RP. The hospital anxiety and depression scale. Acta Psychiatr Scand $1983 ; 67: 361-70$.

38. Gazerani P, Staahl C, Drewes AM, Arendt-Nielsen L. The effects of botulinum toxin type A on capsaicin-evoked pain, flare, and secondary hyperalgesia in 
an experimental human model of trigeminal sensitization. Pain 2006; 122: $315-25$.

39. Tugnoli V, Capone JG, Eleopra R, Quatrale R et al. Botulinum toxin type A reduces capsaicin-evoked pain and neurogenic vasodilatation in human skin. Pain 2007; 130: 76-83.

40. Blersch W, Schulte-Mattler WJ, Przywara S, May A et al Botulinum toxin A and the cutaneous nociception in humans: a prospective, double-blind, placebo-controlled, randomized study, J Neurol Sci 2002; 205: 59-63.

41. Krämer HH, Angerer $\mathrm{C}$, Erbguth $\mathrm{F}$, Schmelz M, Birklein F. Botulinum toxin A reduces neurogenic flare but has almost no effect on pain and hyperalgesia in human skin. J Neurol 2003; 250: 188-193.

42. Schulte-Mattler WJ, Opatz O, Blersch W, May A et al. Botulinum toxin A does not alter capsaicin-induced pain perception in human skin. J Neurol Sci 2007; 260: 38-42.

43. Sycha T, Samal D, Chizh B, Lehr S et al. A lack of antinociceptive or antiinflammatory effect of botulinum toxin A in an inflammatory human pain model. Anesth Analg 2006; 102: 509-16.

44. Voller B, Sycha T, Gustorff B, Schmetterer L et al. A randomized, doubleblind, placebo controlled study on analgesic effects of botulinum toxin $A$, Neurology 2003; 61: 940-944

45. Ranoux D, Gury C, Fondarai J, Mas JL, Zuber M. Respective potencies of Botox and Dysport : a double-blind, randomized, cross-over study in cervical dystonia. J Neurol Neurosurg Psychiatry $2002 ; 72$ : 459-462.

46. Dong M, Yeh F, Tepp WH, Dean C, Johnson EA et al. SV2 is the protein receptor for botulinum neurotoxin A. Science. 2006;312:592-6. 
47. Attal N, Bouhassira D. Mechanisms of pain in peripheral neuropathy. Acta Neurol Scand 1999; Suppl 173: 12-24.

48. Bouhassira D, Lanteri-Minet M, Attal N, Laurent B, Touboul C Prevalence of chronic pain with neuropathic characteristics in the general population. Pain, 2007 ,

49. Torrance N, Smith BH, Bennett MI, Lee AJ. The epidemiology of chronic pain of predominantly neuropathic origin. Results from a general population survey. J Pain $2006 ; 7: 281-9$.

50.Jensen MP, Chodroff MJ, Dworkin RH. The impact of neuropathic pain on health-related quality of life: review and implications. Neurology. 2007;68 :1178-82.

51. Smith BH, Torrance N, Bennett MI, Lee AJ. Health and quality of life associated with chronic pain of predominantly neuropathic origin in the community. Clin J Pain. 2007;23:143-9.

52. Dworkin RH, O'Connor AB, Backonja M, Farrar JT et al. Pharmacologic management of neuropathic pain: evidence-based recommendations. Pain $2007 ; 132: 237-51$.

53. Vadoud-Seyedi J, Simonart T. Treatment of axillary hyperhidrosis with botulinum toxin type A reconstituted in lidocaine or in normal saline: a randomized, side-by-side, double-blind study. Br J Dermatol 2007; 156: 98689. 


\section{Figure 1:}

Photograph showing the BTX-A intradermal injection technique for the painful area in one male patient with post-traumatic radial nerve lesion just before BTX-A injection. Intradermal injections were performed using equidistant grid lines $1.5 \mathrm{~cm}$ apart (marked in black) aiming to cover the area of maximal spontaneous pain (in blue) and the whole area of allodynia (in red). The same procedure was used in patients with irregular areas of allodynia, except that the grid lines were sometimes incomplete in remote angles.

\section{Figure 2:}

Study flow chart

\section{Figure 3}

A: Effects of BTX-A and the placebo on weekly mean pain scores (ITT patients) from 1 to 24 weeks.

${ }^{*} \mathrm{P}<0.05$ versus placebo (post-hoc analyses of variance).

B Proportions of responders to BTX-A and the placebo ( $\geq 50 \%$ pain relief on the basis of weekly mean pain scores) after 4,12 and 24 weeks. There was no responder to the placebo at 4 weeks.

${ }^{*} \mathrm{P}<0.05$ versus placebo

$\underline{\text { C: }}$ Correlation between the baseline severity of thermal deficits (expressed as the difference between warm and cold detection thresholds on the painful side) and the effects of BTX-A on weekly average pain intensity assessed from pain diaries at 12 weeks (expressed as the difference between pain intensity at baseline and 12 weeks). Rho: $-0.69 ; p=0.009$. Similar correlations were found with pain intensity at 4 weeks (Rho: $-0.63 ; p=0.02$ ) and at 24 weeks (Rho: $-0.58 ; p=0.03$ ).

\section{Figure 4:}

Effects of BTX-A and the placebo after 4 and 12 weeks on (A) average intensity of 
allodynia to brush (rated on a 0-100 $\mathrm{mm}$ visual analog scale); (B) mean area of allodynia to brush (in $\mathrm{cm} \mathrm{2)}$; and (C) cold pain thresholds on the painful side. Compared to the placebo, BTX-A attenuated the intensity $(p=0.050)$ and area of allodynia to brush $(p=0.03)$ and reduced cold pain thresholds on the painful side without affecting cold pain thresholds on the normal side, consistent with an effect on cold allodynia $(p=0.029)$ (repeated measures ANOVA at 4 and 12 weeks).

${ }^{*} P<0.05$ compared to the placebo (posthoc analyses) 
Table 1: Patients' characteristics and baseline values.

\begin{tabular}{|c|c|c|}
\hline & BTX-A & Placebo \\
\hline & $\mathrm{n}=15$ & $\mathrm{n}=14$ \\
\hline \multicolumn{3}{|l|}{ Characteristics } \\
\hline Age (years) ( \pm SD) (min-max) & $53.8 \pm 13.9(31-78)$ & $49.7 \pm 15.9(27-76)$ \\
\hline Sex, N (women/men) & $9 / 6$ & $10 / 4$ \\
\hline Pain duration (months \pm SD) (min-max) & $49.2 \pm 31.3(6-108)$ & $50.2 \pm 66.1(12-264)$ \\
\hline Baseline weekly pain intensity (mean \pm SD) & $6.3 \pm 1.8$ & $5.9 \pm 2.0$ \\
\hline \multicolumn{3}{|l|}{ Etiologies of pain $(\mathrm{N})$} \\
\hline -post-traumatic/post-operative & 12 & 13 \\
\hline - postherpetic neuralgia & 3 & 1 \\
\hline \multicolumn{3}{|l|}{ Site of maximal pain $(\mathrm{N})$} \\
\hline - hand & 5 & 7 \\
\hline - foot & 3 & 3 \\
\hline - $\quad$ trunk & 4 & 1 \\
\hline - pelvis & 2 & 2 \\
\hline - elbow & 1 & 1 \\
\hline \multicolumn{3}{|l|}{ Concomitant treatment $(\mathrm{N})$} \\
\hline \multicolumn{3}{|l|}{ (some patients were taking > 1) } \\
\hline None & 5 & 4 \\
\hline Weak analgesics/anti-inflammatories & 2 & 3 \\
\hline Opioid analgesics & 4 & 6 \\
\hline Tricyclic antidepressants & 3 & 4 \\
\hline Antiepileptics & 4 & 4 \\
\hline Benzodiazepines & 4 & 5 \\
\hline
\end{tabular}


Table 2: Individual baseline characteristics of the patients included in the study $(n=29)$ and responses to treatment.

\begin{tabular}{|c|c|c|c|c|c|c|}
\hline $\begin{array}{l}\text { Patients } \\
n^{\circ}\end{array}$ & $\begin{array}{l}\text { Age } \\
\text { (years) }\end{array}$ & $\begin{array}{l}\text { Sex } \\
(F / M)\end{array}$ & $\begin{array}{l}\text { Pain } \\
\text { duration } \\
\text { (months) }\end{array}$ & Aetiology of the nerve lesion & Treatment & $\begin{array}{l}\% \text { reduction } \\
\text { in pain (week } \\
12)^{1}\end{array}$ \\
\hline 1 & 53 & $\mathrm{~F}$ & 12 & Postsurgical (radial nerve) & placebo & -11 \\
\hline 2 & 67 & M & 48 & Postsurgical (sural biopsy) & BTX-A & 50 \\
\hline 3 & 78 & $\mathrm{~F}$ & 24 & Postherpetic neuralgia $^{2}$ & BTX-A & 16 \\
\hline 4 & 45 & $\mathrm{~F}$ & 72 & Trauma (musculocutaneous nerve) & placebo & 46 \\
\hline 5 & 51 & $\mathrm{~F}$ & 36 & Postherpetic neuralgia (thoracic) & BTX-A & 72 \\
\hline 6 & 27 & $\mathrm{~F}$ & 24 & Trauma (peroneal nerve) & placebo & 23 \\
\hline 7 & 55 & $\mathrm{~F}$ & 48 & Postsurgical (post-thoracotomy) & BTX-A & 50 \\
\hline 8 & 73 & $\mathrm{~F}$ & 24 & Postsurgical (herniorrhaphy) ${ }^{3}$ & placebo & 36 \\
\hline 9 & 76 & M & 84 & Postherpetic neuralgia & placebo & -21 \\
\hline 10 & 45 & M & 72 & Trauma (radial nerve) & placebo & -50 \\
\hline 11 & 31 & M & 96 & Trauma (sural nerve) & BTX-A & 38 \\
\hline 12 & 39 & M & 12 & Postsurgical (carpal tunnel syndrome) & BTX-A & 4 \\
\hline 13 & 44 & M & 84 & Postsurgical (carpal tunnel syndrome) & BTX-A & 59 \\
\hline 14 & 51 & $\mathrm{~F}$ & 36 & Postsurgical (carpal tunnel syndrome) & BTX-A & 15 \\
\hline 15 & 40 & $\mathrm{~F}$ & 24 & Trauma (median nerve) & placebo & 58 \\
\hline 16 & 57 & $\mathrm{~F}$ & 36 & Postsurgical (carpal tunnel syndrome) & placebo & 36 \\
\hline 17 & 38 & M & 12 & Trauma (ulnar nerve) & placebo & -9 \\
\hline 18 & 75 & $\mathrm{~F}$ & 48 & Postherpetic neuralgia & BTX-A & 16 \\
\hline 19 & 69 & $\mathrm{~F}$ & 24 & Trauma (peroneal nerve) & placebo & 8 \\
\hline 20 & 75 & $\mathrm{~F}$ & 60 & Postsurgical (carpal tunnel syndrome) & BTX-A & -9 \\
\hline 21 & 44 & $\mathrm{~F}$ & 24 & Postsurgical (carpal tunnel syndrome) & BTX-A & -8 \\
\hline 22 & 54 & M & 18 & Postsurgical (ulnar nerve transposition) & placebo & -12 \\
\hline 23 & 32 & $\mathrm{~F}$ & 12 & Postsurgical (herniorrhaphy) ${ }^{4}$ & placebo & -52 \\
\hline 24 & 51 & $\mathrm{~F}$ & 24 & Postsurgical (carpal tunnel syndrome) & BTX-A & 13 \\
\hline 25 & 46 & M & 84 & Trauma (radial nerve) & BTX-A & 51 \\
\hline 26 & 58 & $\mathrm{~F}$ & 24 & Postsurgical (carpal tunnel syndrome) & placebo & 1 \\
\hline 27 & 29 & $\mathrm{~F}$ & 264 & Postsurgical (ulnar nerve transposition) & placebo & -7 \\
\hline 28 & 54 & M & 6 & Postsurgical (herniorrhaphy) ${ }^{1}$ & BTX-A & 100 \\
\hline 29 & 46 & $\mathrm{~F}$ & 108 & Postsurgical (hysterectomy) ${ }^{2}$ & BTX-A & 42 \\
\hline
\end{tabular}

${ }^{1}$ The percent reduction in pain at week 12 was calculated according to the following formula : 100- (pain score at week 12/baseline score $\times 100$ ). Negative values correspond to an increase in pain and positive values correspond to a decrease in pain. In one patient $\left(n^{\circ} 20\right)$ who stopped the study before week 12, the value obtained at the last follow up visit (week 4) was taken into account. One patient ( $\left.n^{\circ} 28\right)$ had a total pain relief (100\% pain reduction).

${ }^{2}$ Postherpetic neuralgia involved the trunk in all cases.

${ }^{3}$ Lesion of the ilioinguinal nerve

${ }^{4}$ Lesion of the iliohypogastric nerve 


\begin{tabular}{|c|c|c|c|c|c|c|c|c|}
\hline \multirow{2}{*}{$\begin{array}{l}\text { Treatment } \\
\text { Time period }\end{array}$} & \multicolumn{4}{|c|}{ BTX-A } & \multicolumn{4}{|c|}{ Placebo } \\
\hline & Baseline & Week 4 & Week 12 & Week 24 & Baseline & Week 4 & Week 12 & Week 24 \\
\hline Mean pain (VAS) $( \pm S D)$ & $68.6 \pm 15.3$ & $45.0 \pm 30.0^{*}$ & $40.3 \pm 27.3^{*}$ & $47.9 \pm 28.8^{*}$ & $60.0 \pm 18.9$ & $54.0 \pm 22.0$ & $56.4 \pm 26.4$ & $58.5 \pm 26.3$ \\
\hline Pain relief (0-100 \%) ( $\pm S D)$ & & $28.6 \pm 37.5$ & $33.3 \pm 40.9^{*}$ & $25.3 \pm 36.0$ & & $10.0 \pm 16.7$ & $7.7 \pm 14.8$ & $7.6 \pm 15.8$ \\
\hline NPSI symptoms (mean $\pm S D$ ) & & & & & & & & \\
\hline Burning $(0-10)$ & $5.7 \pm 3.3$ & $3.7 \pm 3.2^{*}$ & $3.4 \pm 3.7^{*}$ & $3.9 \pm 3.8$ & $4.7 \pm 3.3$ & $4.6 \pm 3.0$ & $5.1 \pm 3.3$ & $4.6 \pm 3.3$ \\
\hline Squeezing $(0-10)$ & $3.7 \pm 3.3$ & $2.8 \pm 3.1$ & $3.1 \pm 3.5$ & $3.5 \pm 3.7$ & $4.2 \pm 3.3$ & $2.7 \pm 3.4$ & $1.7 \pm 2.7$ & $4.1 \pm 2.7$ \\
\hline Pressure $(0-10)$ & $4.5 \pm 3.8$ & $3.8 \pm 3.1$ & $4.1 \pm 3.6$ & $4.0 \pm 3.5$ & $4.0 \pm 3.0$ & $3.0 \pm 3.0$ & $2.4 \pm 2.8$ & $3.5 \pm 2.9$ \\
\hline Electric shocks $(0-10)$ & $6.5 \pm 3.1$ & $4.1 \pm 3.4^{*}$ & $4.3 \pm 3.7^{*}$ & $4.7 \pm 3.7$ & $5.9 \pm 3.3$ & $5.8 \pm 3.3$ & $5.7 \pm 2.9$ & $5.7 \pm 3.0$ \\
\hline Stabbing $(0-10)$ & $5.5 \pm 3.7$ & $2.9 \pm 3.3^{*}$ & $4.0 \pm 3.3$ & $3.9 \pm 4.0$ & $5.0 \pm 3.7$ & $4.9 \pm 3.5$ & $5.1 \pm 3.9$ & $4.9 \pm 3.4$ \\
\hline Evoked pain to brush $(0-10)$ & $8.0 \pm 1.6$ & $5.4 \pm 3.3^{\star}$ & $5.0 \pm 3.2^{*}$ & $6.0 \pm 3.1$ & $7.8 \pm 2.0$ & $6.8 \pm 2.6$ & $7.1 \pm 2.9$ & $7.0 \pm 3.7$ \\
\hline Evoked pain to pressure $(0-10)$ & $8.4 \pm 1.6$ & $5.7 \pm 3.0$ & $5.9 \pm 2.9$ & $6.3 \pm 2.9$ & $8.0 \pm 2.0$ & $6.5 \pm 3.3$ & $7.1 \pm 2.8$ & $7.1 \pm 2.7$ \\
\hline Evoked pain to cold $(0-10)$ & $5.3 \pm 4.3$ & $3.3 \pm 3.6$ & $2.5 \pm 3.2^{*}$ & $3.3 \pm 3.5$ & $5.2 \pm 3.4$ & $4.1 \pm 3.0$ & $5.6 \pm 3.7$ & $5.5 \pm 3.5$ \\
\hline Tingling $(0-10)$ & $4.5 \pm 4.4$ & $4.2 \pm 3.6$ & $3.4 \pm 3.7$ & $3.9 \pm 3.7$ & $4.6 \pm 3.4$ & $3.9 \pm 2.8$ & $4.5 \pm 3.2$ & $4.2 \pm 3.6$ \\
\hline Pins and needles $(0-10)$ & $6.5 \pm 4.6$ & $4.2 \pm 3.6$ & $4.1 \pm 3.5$ & $4.7 \pm 3.6$ & $5.6 \pm 3.4$ & $4.9 \pm 2.8$ & $5.6 \pm 3.5$ & $5.5 \pm 3.6$ \\
\hline BPI-Interference (mean $\pm S D$ ) & & & & & & & & \\
\hline General activity $(0-10)$ & $6.0 \pm 2.6$ & $4.2 \pm 2.6^{\star}$ & $3.6 \pm 2.9^{*}$ & $4.3 \pm 2.9$ & $5.6 \pm 2.6$ & $5.4 \pm 2.7$ & $5.4 \pm 2.6$ & $5.3 \pm 2.6$ \\
\hline Sleep $(0-10)$ & $4.7 \pm 3.5$ & $2.9 \pm 2.7$ & $2.8 \pm 3.3$ & $3.2 \pm 3.6$ & $5.4 \pm 2.4$ & $4.7 \pm 3.2$ & $3.6 \pm 3.3$ & $4.8 \pm 2.9$ \\
\hline Mood $(0-10)$ & $3.9 \pm 3.9$ & $3.4 \pm 2.8$ & $2.2 \pm 2.3^{*}$ & $3.2 \pm 3.1$ & $4.0 \pm 2.7$ & $4.4 \pm 2.9$ & $4.6 \pm 3.2$ & $4.8 \pm 2.7$ \\
\hline Normal work $(0-10)$ & $5.9 \pm 3.0$ & $4.7 \pm 2.7$ & $4.9 \pm 2.5$ & $5.3 \pm 3.4$ & $6.3 \pm 2.7$ & $5.6 \pm 2.8$ & $5.7 \pm 2.7$ & $5.2 \pm 2.3$ \\
\hline Social relations $(0-10)$ & $3.0 \pm 3.2$ & $2.3 \pm 2.9$ & $2.2 \pm 2.6$ & $2.7 \pm 3.6$ & $2.6 \pm 2.0$ & $2.9 \pm 2.0$ & $3.1 \pm 2.4$ & $2.3 \pm 1.8$ \\
\hline Enjoyment of life $(0-10)$ & $2.7 \pm 2.7$ & $2.3 \pm 2.8$ & $2.1 \pm 2.8$ & $2.4 \pm 3.7$ & $2.6 \pm 2.4$ & $3.1 \pm 3.3$ & $3.0 \pm 3.3$ & $2.3 \pm 3.0$ \\
\hline$H A D$ score $($ mean $\pm S D)$ & & & & & & $111+46$ & & $103+$ \\
\hline Anxiety score & $\begin{array}{l}9.7 \pm 3.6 \\
8.8 \pm 3.8\end{array}$ & $\begin{array}{l}8.0 \pm 4.6 \\
7.5 \pm 3.7\end{array}$ & $\begin{array}{l}8.0 \pm 3.9 \\
8.4 \pm 4.3\end{array}$ & $\begin{array}{l}8.1 \pm 5.6 \\
8.1 \pm 4.4\end{array}$ & $\begin{array}{l}9.2 \pm 4.7 \\
7.7 \pm 3.2\end{array}$ & $\begin{array}{l}11.1 \pm 4.6 \\
7.2 \pm 3.8\end{array}$ & $8.3 \pm 3.7$ & $8.2 \pm 3.9$ \\
\hline Depression score & $8.8 \pm 3.8$ & $1.5 \pm 3.1$ & $8.4 \pm 4.3$ & $8.1 \pm 4.4$ & $1.7 \pm 3.2$ & $1.2 \pm 3.8$ & $8.3 \pm 3.1$ & $8.2 \pm 3.9$ \\
\hline
\end{tabular}

Table 3: Comparison of the effects of BTX-A or placebo on average pain intensity (VAS), pain relief, neuropathic symptoms of the Neuropathic Pain Symptom Inventory (NPSI), 6 items of the Brief Pain Inventory interference (BPI) scores, and anxiety and depression scores of the Hospital Depression and Anxiety (HAD) scale. Data are presented for ITT patients (LOCF analysis). ${ }^{*} p<0.05$ versus placebo. Effects on burning and electric shocks were significant at 24 weeks in analysis of observed data $(p<0.05)$. 
